\title{
Prevention of Pulmonary Cement Embolism by Inferior Vena Cava Filter following Vertebroplasty-related Cement Intravasation
}

\author{
Stephanie Prater ${ }^{*}$, Muhammad Ali Awan ${ }^{2}$, Kristina Antuna ${ }^{2}$, Julio Zayas Colon ${ }^{1}$ \\ 1. Department of Radiology, Aventura Hospital \& Medical Center, Miami, FL, USA \\ 2. Kiran C. Patel School of Allopathic Medicine, Nova Southeastern University, Davie, FL, USA
}

* Correspondence: Stephanie Prater, MD, Aventura Hospital \& Medical Center. Department of Radiology. 20900 Biscayne Blvd. Aventura, FL 33180, USA

( $\triangle$ sprater16@yahoo.com)

Radiology Case. 2021 Apr; 15(4):17-27 :: $\quad$ DOI: 10.3941/jrcr.v15i4.4139

\begin{abstract}
A 77 year old woman with recent history of vertebroplasty for treatment of multiple osteoporotic lumbar vertebral body compression fractures presented for post-procedure care. A series of radiographs and cross-sectional imaging of the lumbar spine revealed an unexpected finding of cured bone cement within a small lumbar vertebral vein, the inferior vena cava and within the spokes of an inferior vena cava filter which had originally been placed two years earlier. Inferior vena cava filters have become the standard of care to prevent pulmonary embolism in the setting of deep venous thrombosis. However, cases of foreign materials becoming entrapped in filters are uncommon despite the documented frequency of intravasation of bone cement into the circulatory system following vertebroplasty procedures. This case is significant because it illustrates the rare occurrence of an inferior vena cava filter capturing intravasated bone cement and preventing its migration to the pulmonary circulation.
\end{abstract}

\section{CASE REPORT}

\section{CASE REPORT}

Here we present a case of a 77-year-old woman with a history of osteoporosis and deep vein thrombosis (DVT) for which a temporary inferior vena cava (IVC) filter had been placed two years earlier but never retrieved. The patient had recently undergone percutaneous vertebroplasty (PVP) at an out-of-state facility for treatment of three compression fractures which had been determined to be the source of severe low back pain. She presented several days after her procedure with pain and redness of the skin over the access site. She denied back pain, chest pain, and shortness of breath.
A series of lumbar spine radiographs were performed as a part of the initial evaluation (Figure 1). Dense bone cement was visualized over the second, fourth, and fifth lumbar vertebral bodies, consistent with her recent vertebroplasty. Additionally, radio-opaque material was visualized throughout the length of a tiny vein extending from the vertebral body into the adjacent inferior vena cava. More surprising, though, was the appearance of this radiopaque cement trapped within the IVC filter.

Given this unusual presentation, unenhanced computed tomography (CT) of the abdomen was performed and 
subsequently confirmed the presence of the bone cement within the vertebral bodies, small bridging veins of the anterior external vertebral venous plexus, IVC and caval filter (Figure 2). At an outpatient follow up approximately two weeks after initial presentation, the patient reported resolution of the skin changes and denied any further complaint. Treatment options to address the cemented IVC filter were discussed at that time including both non-surgical and surgical retrieval. Ultimately, the patient opted to forgo further intervention in favor of observation.

\section{DISCUSSION}

\section{Etiology \& Demographics:}

Polymethyl methacrylate, colloquially known as bone cement, is widely used to anchor prostheses during joint replacement surgery [1]. It is also used for vertebroplasty, a minimally invasive procedure in which bone cement is injected into a diseased vertebral body [2]. This technique provides pain relief and strengthens vertebral bodies weakened by trauma, osteoporosis, and malignancy [2]. PVP has gained widespread popularity for the treatment of compression fractures since its initial description over 30 years ago [2]. More than 250,000 vertebroplasty and kyphoplasty procedures were performed in the United States between 2009 and 2014 [2]. While infrequent in procedures such as hip arthroplasty, leakage of bone cement into the circulation has been frequently observed during and after vertebroplasty [3]. Cement "migration" is the most frequently reported complication of PVP [3]. Cement leakage outside the vertebral body during PVP has been noted to occur in up to $73 \%$ of cases, with venous intravasation in up to $24 \%$ of cases [4].

Given the fact that older age and female sex are the biggest risk factors for the development of osteoporosis and thus compression fractures, it should come as no surprise that female patients accounted for $73 \%$ of vertebroplasty procedures between the years of 2006 and 2014 [5]. Similarly, in the same time frame, $87 \%$ of vertebroplasty procedures were performed on patients over age 65 (54\% aged 65-85 and $33 \%$ older than 85) [5]. However, age and gender-matched comparison studies have revealed no specific age or sexrelated predilection for vertebroplasty-related bone cement migration [6].

Intravasation of polymethyl methacrylate may result from many factors. It may in part be attributed to the nature of the venous drainage at the site of injection. The spine is highly vascularized with numerous intraosseous vertebral veins that form a valveless, freely communicating plexus. Osteoporotic demineralization of vertebral bodies also plays a role in cement migration as compression fractures disrupt the osseous cortex and destroy internal trabecular scaffolding, thereby reducing bony hindrance of venous drainage. Loss of intrinsic structure allows for a direct shunt of cement polymer into adjacent vasculature and subsequently, into circulation [7].

The increasing ease with which cement is able to move through a demineralized vertebral body highlights the importance of appropriate cement viscosity [7]. Cement has two components: an ampule of liquid methyl methacrylate and a fine powder consisting of a mix of polymethyl methacrylate and barium sulfate [7]. These components are combined to form a consistency similar to that of toothpaste. The viscosity (thickness) of the cement compound progressively increases as a result of polymerization; the rate of this process depends on several difficult-to-evaluate factors, including the ambient temperature and the quantity of the solvent [7]. A paste is preferred to a liquid consistency because the latter increases the risk of polymethyl methacrylate leakage into the circulatory system [7].

The size of the needle used to inject the bone cement polymer can also influence the incidence of intravasation [7]. If a small gauge needle is used, more liquidity and hence, less viscosity, is necessary to overcome the resistance against the small diameter needle which as mentioned above, further increases the risk of leakage [7].

Finally, the volume of cement polymer plays an important role in prevention of cement migration. This is because studies have shown the pain relief benefit of vertebroplasty is not proportional to the degree of lesion filling by bone cement [7]. As such, it is important to use the smallest volume of bone cement possible [7]. The same studies have revealed that complications related to bone cement injection were primarily related to an excessive volume of bone cement [7]

Inferior vena cava filters are an implantable medical device used to prevent pulmonary embolus in patients with DVT or at high risk of developing DVT [8]. They work by capturing thrombotic material traveling cephalad from the veins of the lower extremities and pelvis [8]. While the benefit of IVC filters is a highly debated topic in numerous medical circles, there is no denying the fact that more than 50,000 of these devices are placed in the United States each year [8].

Despite the relative frequency with which IVC filters are placed, cases of foreign materials being trapped by filters have not been frequently reported. To the best of our knowledge, there are only three reported cases of polymethyl methacrylate entrapment by filters following vertebroplasty in the current literature $[4,11,12]$. Given the increasing number of patients undergoing both IVC filter placement and vertebroplasty, the frequency of IVC filter capture of intravasated bone cement could, theoretically, be on the rise.

\section{Clinical findings:}

Although most patients with minor vertebroplasty-related bone cement intravasation are asymptomatic, some disastrous consequences of cement embolism have been reported, including renal failure, pulmonary infarct, ischemic stroke, and cardiac perforation $[3,7,9,10]$. These cases, however, were all reported in patients without IVC filters.

Three reported cases of bone cement entrapment by IVC filters following vertebroplasty have been published with the earliest dating back to 2006. In reports by Herbstreit (2006) and Agko (2010), bone cement was visualized within an IVC filter days to weeks following vertebroplasty [4,11]. A third report by $\mathrm{Li}$ (2013) describes direct observation of venous intravasation of polymethyl methacrylate from the vertebral body into the IVC as well as the subsequent trapping of the 
cement material within the filter in real-time under fluoroscopy [12].

In all three cases, the presence of a caval filter prevented the embolization of cement material into downstream vasculature and organs $[4,11,12]$. Unfortunately, these cases were not entirely without clinical consequence. In Herbstreit's report, endovascular retrieval of the cemented filter was impossible; the patient underwent surgical extraction of the filter via open cavotomy [4]. In the Agko report, the cement fragment was retrieved from the filter via snare but the fragment was too large to be retracted within the small diameter snare sheath and ultimately, open venotomy was necessary for removal [11]. Invasive surgical exploration of the retroperitoneal cavity to search for hemorrhage was necessitated by an episode of hypotension during the snare procedure, though fortunately no vasculature injury was found [11]. In the case reported by $\mathrm{Li}$, due to the patient's history of malignancy, a permanent caval filter had been placed such that removal was not considered [12]. However, they reported no adverse complications of cement trapping by the filter, both in the immediate post-operative period and throughout 8 months of follow up [12].

\section{Treatment \& Prognosis:}

Anticoagulation is the mainstay of treatment for bland thrombus in the IVC [13]. While bland thrombosis of a caval filter may be amenable to treatment via anticoagulation or more aggressive catheter-directed thrombolysis, this strategy would be ineffective in the case of bone cement embolus because polymethyl methacrylate is not thrombin-based. Theoretically, anticoagulation may offer potential benefit as this therapy could reduce the risk of thrombosis due to altered blood flow dynamics resulting from partial occlusion of the IVC by a cemented filter. However, it should be noted that many patients undergo IVC filter placement specifically due to of their inability to tolerate anticoagulation.

Because of the rarity of vertebroplasty-related cement intravasation with subsequent entrapment by an IVC filter, there is no gold standard for treatment. There are, however, measurements that can be taken to reduce the risk of intravasation. As previously mentioned, assuring adequate cement viscosity, using a larger needle gauge, and the smallest volume of cement possible all contribute to decreased risk of intravasation [7]. Patient positioning is also clinically important. Studies have shown that intraosseous pressure is increased via compression of the inferior vena cava by placing the patient in the prone position [7]. Creation of this "retrograde congestion" has been shown to reduce the risk of bone cement intravasation [7]. Additionally, good-quality fluoroscopy is essential because it may allow for early detection of cement leakage and thus, discontinuation of the procedure prior to extrusion of large volumes of cement [7]. Finally, vertebral venography has been advocated as a preprocedural exam to be performed prior to PVP [7]. Its value, however, is considered somewhat contentious. Although venography can document sites of potential leakage during subsequent cement application, stagnant contrast agent renders the cement injection more difficult to monitor, and an allergic reaction to contrast agent remains a potential risk [7].
Interestingly, one interventional group has described a novel endovascular technique for retrieval of migrated bone cement within the inferior vena cava [14]. Isaak et al.'s method involves deploying a novel woven "basket" device to capture fragments of migrated cement and once snared, the basket and contained bone cement are recovered [14]. However, this novel procedure was only performed on cadavers and was only intended for retrieval of cement from the IVC lumen, not from the tines of a filter.

Theoretically, if not completely adherent to the filter, one might consider attempting to snare the cement fragments from within the filter tines. However, this technique may be limited by cement fragment size and shape, as was the case for Agko's group [11]. As previously mentioned, that group was able to snare individual cement fragments from the filter but their size prevented trans-catheter retrieval such that open venotomy was required to remove one of the larger cement fragments [11].

Hypothetically, one could attempt to retrieve the filter and contained cement as a single unit. However, it is doubtful that such a filter would collapse neatly within a snare sheath and if it did fit, retrieval of the snare/filter/cement complex through the vascular access point may prove difficult.

Surgical intervention, removal of a cemented filter via open cavotomy, would provide definitive treatment as was the case in Herbstreit's report [4]. However, this procedure is highly invasive and carries a high risk of morbidity and mortality [4].

Abandonment of a cemented filter within the cava is the final potential management option. Deserting the cemented filter would likely impact flow speed and dynamics in a fashion similar to a thrombosed caval filter, the symptoms of which are generally proportional to the degree of filter occlusion [15].

\section{Differential Diagnosis:}

Any filling defect of the IVC, intrinsic or extrinsic, real or perceived, can be included in the differential diagnosis for migrated intraluminal bone cement. These entities include bland thrombus, tumor thrombus, fat embolism, calcification of the IVC itself, and imaging artifacts.

\section{Bland thrombus of the IVC:}

The most common true filling defect of the IVC is bland thrombus $[16,17]$. Bland thrombus in the IVC can be isolated, but it more often spreads from the veins of the lower extremities $[16,17]$. Thrombi may be idiopathic or the result of hypercoagulability, venous stasis, congenital IVC anomalies, or the presence of a foreign body [18]. Hypercoagulability state may be due to oral contraceptives, antiphospholipid syndrome, paroxysmal nocturnal hemoglobinuria, vascular injury, paraneoplastic syndromes, smoking, obesity, pregnancy, hormone replacement therapy, nephrotic syndrome, and various coagulopathies, such as factor $\mathrm{V}$ Leiden deficiency and protein $\mathrm{C}$ resistance [18]. A preexisting clot in nearby vasculature structures, such as DVT and more rarely, Budd-Chiari, may result in clot extension into the IVC [18]. Venous stasis may be a product of external 
compression of the IVC by extrinsic masses, abdominal aortic aneurysm, and retroperitoneal hematoma / neoplasms / fibrosis / adenopathy [18]. Foreign bodies, such as venous catheters, may also represent a source of thrombus formation [18]. Though relatively rare and usually asymptomatic, various congenital IVC anomalies may also contribute to caval thrombi [18]. Furthermore, chronic occlusion can lead to calcification of the thrombus as well as pericaval and periaortic collateral formation [13].

\section{Tumor and tumor thrombus of the IVC:}

Malignancies such as renal cell carcinoma, hepatocellular carcinoma, Wilms tumor, and adrenocortical carcinoma can extend directly into the IVC from adjacent organs [16]. Occasionally, intraluminal leiomyosarcoma may arise as primary malignancy of the IVC [16]. Features that distinguish malignant from bland thrombus include presence of a contiguous adjacent mass, enhancement of the filling defect, vessel expansion, and uptake of fluorodeoxyglucose on positron emission tomography (PET) $[16,17]$. It is important to note that malignancy predisposes to thrombosis due to hypercoagulability such that bland downstream thrombus may coexist with malignant thrombus [17].

\section{Fat embolism:}

Fat embolism is the presence of fat particles within the circulatory system, usually in the form of bone marrow following orthopedic trauma [19]. While most often associated with long bone fractures, rare cases of fat embolism have been reported following bone marrow transplantation, osteomyelitis, pancreatitis, alcoholic fatty liver, and even liposuction [19]. The lipids released into the bloodstream are typically microscopic but a few cases of macroscopic fat within the IVC have been described [19]. A rare source of such emboli is migratory fat globules created via fragmentation of a large renal angiomyolipoma [20].

\section{Calcification of the IVC wall:}

IVC calcification has been described in neonates and is associated with disseminated intravascular coagulation, placentofetal embolus, hypotensive shock, dehydration, focal infection, septicemia, malignancy, and structural anomalies [21]. It is extremely rare in adults and only a few cases have been reported in literature [21]. Most patients are asymptomatic and the calcification is usually detected incidentally [21].

\section{Artifactual filling defect of the IVC:}

There are three main varieties of IVC pseudolesion: pseudothrombosis, pseudolipoma, and admixture artifact. Pseudothrombus, a well-described artifact which is classically associated with catheter venography, can mimic the appearance of bland IVC thrombus [22]. It is caused by laminar flow of enhanced blood from the renal veins streaming parallel to the column of unopacified blood returning from the lower body [22]. The pseudolipoma, sometimes referred to as a paracaval lipoma, is a rarer and more recently described pseudolesion of the IVC seen on magnetic resonance imaging (MRI) or CT which represents a partial volume artifact of pericaval fat above the caudate lobe rather than a true intraluminal lesion [23]. This artifact is common in patients with chronic liver disease in whom prominent pericaval fat collections commonly develop [23].
Coronal MRI or reformatted CT images help to confirm the true nature of this finding [23]. Finally, admixture artifacts result from poorly enhanced blood, such as from an accessory hepatic vein, flowing into an opacified IVC or from laminar reflux of opacified blood from the heart into the IVC, usually in the setting of right heart failure or a high injection rate [22]. Delayed images that demonstrate resolution of filling defects are usually sufficient to confirm the artifactual nature of pseudolesions, but occasionally, problematic cases may require further evaluation with flow-sensitive or delayed contrast-enhanced MRI and CT sequences, respectively [23].

\section{Imaging Findings:}

\section{Ultrasound:}

For patients with suspected caval thrombosis and symptoms of lower extremity pain/swelling, imaging with duplex ultrasound (US) of the IVC is generally the first diagnostic examination [18]. Unfortunately, US is somewhat limited for evaluation of the IVC, due in part to operator experience, bowel gas, and endomorphic patient body habitus [18]. When detectable, however, bland thrombus appears as a focus of varying echogenicity within an anechoic IVC lumen [13]. Bland thrombus will become increasingly echogenic with chronicity [13]. An acute bland thrombus may expand the vessel while a chronic one may shrink the vessel [16]. If bland thrombus can be ruled out, consideration should be given to tumor thrombus of the IVC, particularly in patients with a history of malignancy. In such cases, sonographic examination of the IVC may reveal an echogenic soft tissue mass in the IVC lumen, with or without expansion of the vessel, and associated color Doppler flow indicating vascularity within the mass [16]. In the absence of known malignancy and bland thrombosis, recent trauma may raise suspicion for fat embolism, the sonographic appearance of which is rather nonspecific - an echogenic focus within the IVC lumen $[19,24]$. Finally, symptoms of IVC occlusion in the setting of recent PVP may raise suspicion for a complication such as intravasation of bone cement. In the setting of cement thrombus, ultrasound of the IVC may reveal a hyper-echoic focus of cement with associated posterior acoustic shadowing due to its density. Additional sonographic clues that suggest IVC occlusion by any of the aforementioned etiologies include a monophasic waveform on Doppler mode, decreased IVC blood flow velocity, and inability to compress the vessel [13].

\section{X-Ray:}

Conventional radiography is not particularly helpful in the diagnosis of most causes of IVC occlusion. However, in the setting of intravasated cement, frontal and lateral thoracolumbar spine radiographs may demonstrate an irregular focus of radiopaque bone cement in the topography of the IVC with associated linear foci of radiopaque bone cement within the vasculature of the anterior external vertebral venous plexus bridging from the spine to the IVC [12]. A chronic, calcified bland thrombus could potentially be seen in a similar manner - an irregular radiopaque focus in the general topography of the IVC though unconnected to the spine [13]. Calcification of the IVC, which is relatively rare, would appear more extensive and plaque-like [21] 
CT:

$\mathrm{CT}$ is a superior imaging modality for characterizing the filter-thrombus relationship, including the extent of clot burden and the degree of vessel occlusion [18]. A bland thrombus in the IVC is best seen on contrast-enhanced CT acquired in the portal venous phase (60-70 seconds after contrast injection) where it appears as a low attenuation filling defect within the contrast-opacified IVC lumen [18]. In the setting of tumor thrombus, one may see an enhancing soft tissue mass in the IVC lumen which will mostly expand the vessel [16]. The tumor may be isolated, arising directly from the IVC, or spread contiguously into the IVC through the venous vasculature of a nearby organ such as the kidney, liver, or adrenal glands [16]. However, in the case of intravasated bone cement, the intrinsic high density of the polymethyl methacrylate would likely render it indistinguishable from the high attenuation contrast. As such, non-contrast CT would be the study of choice for evaluation of migrated bone cement which would appear as an irregular focus of high density within the hypo-dense IVC, and if present, within the tines of an IVC filter as was observed on our imaging studies [11]. It is important to note that the presence of intravenous contrast can create artifactual filling defects as the result of laminar flow of enhanced blood from the renal veins streaming parallel to the column of unopacified blood returning from the lower body or laminar reflux of opacified blood into the IVC due to right heart failure [22].

\section{MRI:}

Contrast-enhanced MRI represents a reliable technique for evaluating the IVC but limited availability and cost considerations prohibit its routine use [13]. Bland thrombus, in the acute phase, will appear as a focus of high T1 weighted images (T1WI) and T2 weighted images (T2WI) signal intensity while chronic bland thrombus has a high T1WI and low T2WI signal intensity and calcified thrombi will demonstrate gradient echo susceptibility artifact [13]. Bland thrombus is not associated with restricted diffusion weight images (DWI) or contrast enhancement [13]. Tumor thrombus, on the other hand, will appear as an enhancing soft tissue mass in the IVC with associated restricted DWI [16]. Intrinsic T1WI/T2WI signal characteristics will depend on tumor type [16]. Fat embolism will appear as a non-enhancing, T1WI/T2WI hyper-intense focus within the IVC lumen that will saturate on fat saturation sequences [19,20,24]. It is important to note that familiarity with certain pitfalls in magnetic resonance imaging of the IVC is critical to avoid missed or over-diagnosis [17,22,23]. Misinterpretation is primarily related to a flow-related phenomenon at the level of the renal veins manifesting as a pseudo-filling defect (similarly to previously described artifactual filling defects seen on CT) due to mixing of the enhanced blood in the renal veins and the unenhanced venous return from the lower body $[17,22,23]$. Furthermore, the presence of an IVC filter may create ferromagnetic artifact which may limit the reader's ability to assess IVC patency [13]. This fact, combined with bone cement's intrinsic lack of T1WI/T2WI signal would theoretically render this modality less useful than contrastenhanced CT for detection of vertebroplasty-related bone cement migration.

\section{${ }^{18}$ F-FDG PET:}

Nuclear imaging, namely ${ }^{18} \mathrm{~F}$-FDG PET, is ineffective for evaluation of all of the aforementioned causes of IVC thrombosis except tumor thrombus; it is the only etiology that will demonstrate radiotracer uptake [16].

\section{Catheter venography:}

Catheter venography is generally performed intraoperatively during catheter-directed thrombolysis or mechanical thrombectomy. Though considered the gold standard for diagnosis of IVC occlusion, it is a relatively invasive method that can be challenging if related pathology is present at the femoral and or popliteal access sites [13]. On injection of contrast, the IVC will be become opacified and if a thrombus (of any type - bland, tumor, fat, or bone cement) is present it will appear as an intraluminal filling defect [13]. Non-occlusive entities, such as IVC calcification, would not demonstrate a filling defect because the calcium is distributed throughout the walls of the vessel rather than the lumen, though the lumen itself may appear irregular [21].

\section{TEACHING POINT}

Venous intravasation of bone cement is a common complication of vertebroplasty and the presence of an IVC filter may effectively prevent bone cement embolization into nearby organs.

\section{REFERENCES}

1. Vaishya R, Chauhan M, Vaish A. Bone cement. J Clin Orthop Trauma. 2013;4(4):157-163. PMID: 26403875

2. Laratta JL, Shillingford JN, Lombardi JM, et al. Utilization of vertebroplasty and kyphoplasty procedures throughout the United States over a recent decade: an analysis of the Nationwide Inpatient Sample. J Spine Surg. 2017;3(3):364370. PMID: 29057344

3. Yoo KY, Jeong SW, Yoon W, Lee J. Acute respiratory distress syndrome associated with pulmonary cement embolism following percutaneous vertebroplasty with polymethylmethacrylate. Spine (Phila Pa 1976). 2004;29(14):E294-E297. PMID: 15247590

4. Herbstreit F, Kühl H, Peters J. A cemented caval vein filter: case report. Spine (Phila Pa 1976) 2006;31:E917-E919. PMID: 17108822

5. Laratta JL, Shillingford JN, Lombardi JM, et al. Utilization of vertebroplasty and kyphoplasty procedures throughout the United States over a recent decade: an analysis of the Nationwide Inpatient Sample. J Spine Surg. 2017;3(3):364370. PMID: 29057344

6. Zhan Y, Jiang J, Liao H, Tan H, Yang K. Risk Factors for Cement Leakage After Vertebroplasty or Kyphoplasty: A 
Meta-Analysis of Published Evidence. World Neurosurg. 2017;101:633-642. PMID: 28192270

7. Chung SE, Lee SH, Kim TH, Yoo KH, Jo BJ. Renal cement embolism during percutaneous vertebroplasty. Eur Spine J. 2006;15 Suppl 5(Suppl 5):590-594. PMID: 16362386

8. Grewal S, Chamarthy MR, Kalva SP. Complications of inferior vena cava filters. Cardiovasc Diagn Ther. 2016;6(6):632-641. PMID: 28123983

9. Marden FA, Putman CM. Cement-embolic stroke associated with vertebroplasty. AJNR Am J Neuroradiol. 2008 Nov;29(10):1986-8. PMID: 18617589

10. Kim SY, Seo JB, Do KH, Lee JS, Song KS, Lim TH. Cardiac perforation caused by acrylic cement: a rare complication of percutaneous vertebroplasty. AJR Am J Roentgenol 2005;185:1245-1247. PMID: 16247143

11. Agko M, Nazzal M, Jamil T, Castillo-Sang M, Clark P, Kasper G. Prevention of cardiopulmonary embolization of polymethylmethacrylate cement fragment after kyphoplasty with insertion of inferior vena cava filter. J Vasc Surg 2010;51:210-213. PMID: 19837540

12. Li Z, Ni RF, Zhao X, Yang C, Li MM. Cement embolus trapped in the inferior vena cava filter during percutaneous vertebroplasty. Korean J Radiol. 2013;14(3):451-454. PMID: 23690712

13. Hollingsworth CM, Mead T. Inferior Vena Caval Thrombosis. StatPearls [Internet]. January 2020. PMID: 30725860

14. Isaak A, Takes M, Kingsmore D, Gürke L. Endovascular Retrieval of Intracaval Cement: A Fishing Net Technique. Cardiovasc Intervent Radiol. 2018;41(12):1958-196. PMID: 30128782

15. Sildiroglu O, Ozer H, Turba CK. Management of the thrombosed filter-bearing inferior vena cava. Semin Intervent Radiol. 2012 March; 29(1): 57-63. PMID: 23449290

16. Quencer KB, Friedman T, Sheth R and Oklu R. Tumor thrombus: incidence, imaging, prognosis and treatment. Cardiovac Diagn Ther. 2017 Dec; 7(Suppl3): S165-S177. PMID: 29399520

17. Kaufman LB, Yeh BM, Breiman RS, Joe BN, Qayyum A and Coakley FV. Inferior Vena Cava Filling Defects on CT and MRI. Am Journal of Roentgenology. 2005 Sept; 185(3):717-726. PMID: 16120925

18. Alkhouli A, Morad M, Narins CR, Raza F, Bashir R. Inferior Vena Cava Thrombosis. JACC: Cardiovascular Interventions. 2016 April; 9(7). PMID: 26952909

19. Kwiatt ME, Seamon MJ. Fat embolism syndrome. Int J Crit Illn Inj Sci. 2013;3(1):64-68. PMID: 23724388

20. Celik SU, Kocaay AF, Sevim Y, Cetinkaya OA, Atman ED, Alacayir I. Renal Angiomyolipoma With Caval Extension and Pulmonary Fat Embolism: A Case Report. Medicine (Baltimore). 2015;94(31):e1078. PMID: 26252271

21. Kareem H, Devasia T, Nayak K, Agarwal S. Unexplained extensive calcification of the venae cavae extending into the right atrium causing partial obstruction of the tricuspid valve. BMJ Case Rep. 2014;2014:bcr2014204070. Published 2014 Jun 5. PMID: 24903969

22. Zimmerman S, Fishman EK. (2015). Pearls and pitfalls in cardiovascular imaging: Pseudolesions, artifacts and other difficult diagnoses. Cambridge University Press. ISBN (electronic): 9781139152228; ISBN (print): 9781107023727

23. Sheth S, Fishman EK. Imaging of the Inferior Vena Cava with MDCT. American Journal of Roentgenology 2007 189:5, 1243-1251. PMID: 17954667

24. Liu P, Armstrong P, Skippen P. Post-traumatic fat embolism in the inferior vena cava. Can Assoc Radiol J. 1990;41(5):303-304. PMID: 2207793. 


\section{FIGURES}

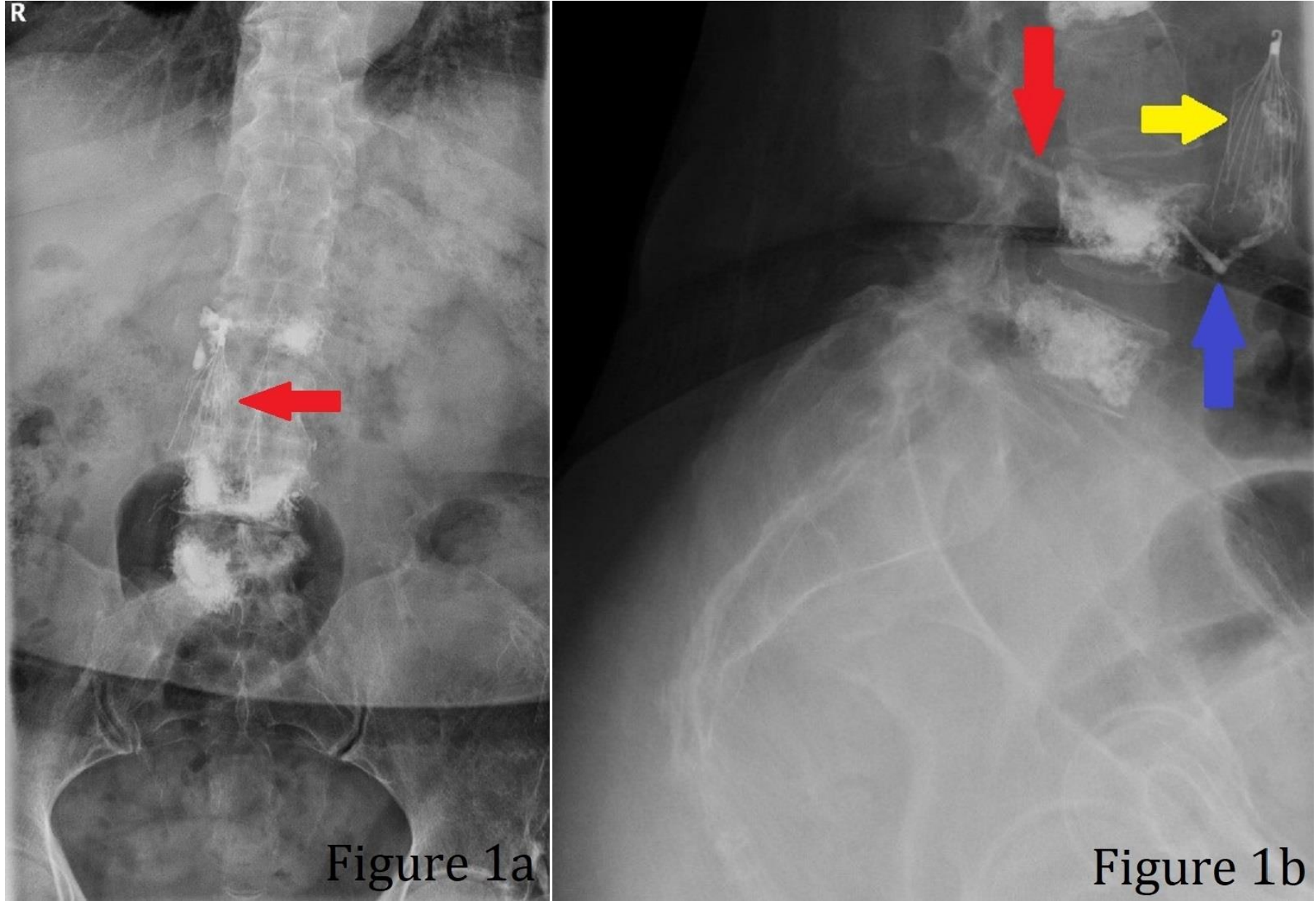

Figure 1: 77 year old woman with vertebroplasty-related intravasation of bone cement into the inferior vena cava via small bridging veins of the anterior external vertebral venous plexus at the L4 level with subsequent entrapment by an IVC filter.

a)

Findings: AP radiograph of the lumbar spine status post L2, L4 and L5 vertebroplasty. Intravasated cement is seen within the spokes of an adjacent IVC filter (red arrow).

Technique: GE XR220. 40 mAs. 80 kVp.

b)

Findings: Lateral radiograph of the lumbar spine status post L2, L4 and L5 vertebroplasty. Linear opacities representing intravasated bone cement are seen extending dorsally along the catheter track (red arrow) and ventrally along anterior external vertebral venous plexus draining into the inferior vena cava (blue arrow). Cement is seen within the spokes of an adjacent IVC filter (yellow arrow).

Technique: GE XR220. 60 mAs. 90 kVp. 


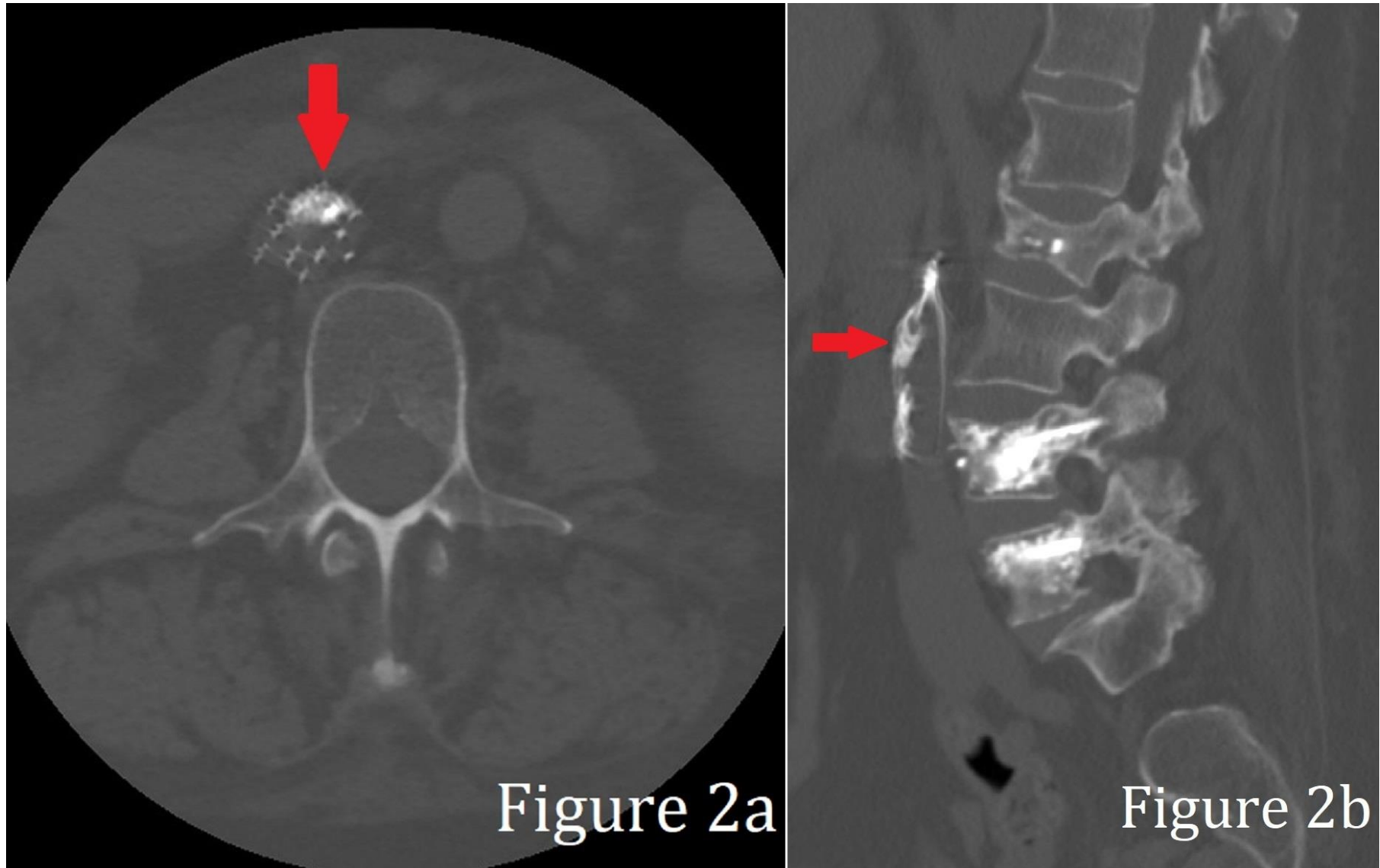

Figure 2: 77 year old woman with vertebroplasty-related intravasation of bone cement into the inferior vena cava via small bridging veins of the anterior external vertebral venous plexus at the L4 level with subsequent entrapment by an IVC filter.

a)

Findings: Axial non-contrast CT of the lumbar spine at the level of L3 demonstrates a focus of intravasated bone cement within the spokes of an IVC filter (red arrow).

Technique: GE Optima CT660. 479 mA. 120 kVp. 2.5 mm slice thickness.

b)

Findings: Sagittal non-contrast CT of the lumbar spine status post L2, L4 and L5 vertebroplasty. Intravasated cement is seen within the spokes of an adjacent IVC filter (red arrow).

Technique: GE Optima CT660. 479 mA. 120 kVp. 3 mm slice thickness. 


\begin{abstract}
Etiology
Bone cement intravasation may in part be attributed to the nature of the venous drainage at the site of injection [7].

- The spine is highly vascularized with numerous intraosseous vertebral veins which form a valveless, freely communicating plexus [7].

- Osteoporosis and demineralization of vertebral bodies also plays a role in cement intravasation as compression fractures destroy internal trabecular scaffolding and thereby reduce bony hindrance of venous drainage. This allows a direct shunt of still-viscous cement into adjacent vasculature and subsequently, into circulation [7].

- Moreover, a small gauge needle is used to inject the compressed vertebral bodies. In order to overcome the resistance against the small-diameter needle, more liquidity and hence, less curability, is required which further increases the risk of extrusion [7].
\end{abstract}

\begin{tabular}{l|l} 
Incidence & $-\quad$ Cement "leakage" or "migration" is the most frequently reported complication of PVP [3]. \\
- & The rate of cement leakage outside the vertebral body during PVP occurs in up to 73\% of cases with \\
& venous leakage in up to $24 \%$ of cases [4]. \\
- & Only 3 cases of bone cement entrapment by IVC filter are reported in the literature [4, 11, 12].
\end{tabular}

Gender Ratio - Female patients accounted for 73\% of vertebroplasty procedures between the years of 2006 and 2014 [5]. However, when accounting for differences in sex, no gender predilection for bone cement migration has been identified [6].

\begin{tabular}{|c|c|}
\hline Age Predilection & $\begin{array}{l}\text { - Between } 2006 \text { and } 2014,54 \% \text { of vertebroplasty procedures were performed on patients aged } 65-85 \text { and } \\
33 \% \text { were performed on patients older than } 85 \text { [5]. } \\
\text { - However, when accounting for differences in age, no age predilection for bone cement migration has been } \\
\text { identified [6]. }\end{array}$ \\
\hline Risk Factors & $\begin{array}{l}\text { The presence of osteoporotic compression fractures (osseous cortical disruption and trabecular } \\
\text { destruction), low cement viscosity, small gauge injection needle and high volume of injected cement have } \\
\text { been determined to place patients at high risk for cement leakage after vertebroplasty [7]. }\end{array}$ \\
\hline Trea & $\begin{array}{l}\text { There is no gold standard for treatment for venous migration of bone cement following vertebroplasty. } \\
\text { Patients are generally asymptomatic and require no treatment [3]. } \\
\text { Treatment, when necessary, is focused on controlling the symptoms of bone cement embolization into the } \\
\text { vascular structures of major organs }[3,7,9,10] \text {. } \\
\text { - Several interventional strategies have been described for retrieval of migrated bone cement fragments } \\
\text { though this is typically unnecessary }[4,11,14] \text {. }\end{array}$ \\
\hline Prog & $\begin{array}{l}\text { - } \quad \text { Bone cement migration is typical non-life threatening and patients are generally asymptomatic [3]. } \\
\text { - If symptoms of more serious sequelae of bone cement migration are successfully managed, prognosis is } \\
\text { generally considered good. However, rare adverse outcomes have been described }[3,7,9,10] \text {. }\end{array}$ \\
\hline ings & $\begin{array}{l}\text { X-Ray: Irregular focus of radiopaque bone cement in the topography of the IVC with associated linear } \\
\text { foci of radiopaque bone cement within the vasculature of the anterior external vertebral venous plexus } \\
\text { bridging from the spine to the IVC [12]. } \\
\text { - US: echogenic focus of bone cement within the IVC lumen with extensive posterior acoustic shadowing } \\
\text { due to the inherent density of polymethyl methacrylate. } \\
\text { - Unenhanced CT: irregular hyper-dense focus of bone cement within the spokes of an IVC filter with } \\
\text { associated linear foci of hyper-dense bone cement within the vasculature of the anterior external vertebral } \\
\text { venous plexus bridging from the spine to the IVC [11]. } \\
\text { - Contrast-enhanced CT: Similar findings to unenhanced CT in the arterial phase, potential non- } \\
\text { visualization of the cement thrombus due to contrast opacification of the IVC in the portal venous phase. } \\
\text { - Contrast-enhanced MRI: In the absence of an IVC filter, the bone cement thrombus will appear as a } \\
\text { T1WI/T2WI hypo-intense focus within an opacified IVC. Limited visualization of cement thrombus in the } \\
\text { absence of contrast or with the presence of an IVC filter due to filter-related ferromagnetic artifact. } \\
\text { - Conventional Venography: filling defect within the contrast opacified IVC lumen, representing migrated } \\
\text { bone cement. }\end{array}$ \\
\hline
\end{tabular}

Table 1: Summary table for IVC Cement Thrombus. 


\begin{tabular}{|c|c|c|c|c|c|c|}
\hline & CT & MRI & US & PET & X-Ray & $\begin{array}{l}\text { Catheter } \\
\text { Venography }\end{array}$ \\
\hline $\begin{array}{l}\text { Bland } \\
\text { Thrombus }\end{array}$ & $\begin{array}{l}\text { Unenhanced CT is of } \\
\text { limited utility unless the } \\
\text { thrombus has calcified in } \\
\text { which case a hyper-dense } \\
\text { focus will be seen within } \\
\text { the IVC lumen. With } \\
\text { more acute thrombi, } \\
\text { contrast-enhanced CT will } \\
\text { show a non-enhancing } \\
\text { hypo-dense focus within } \\
\text { an opacified IVC lumen } \\
\text { (portal venous phase) } \\
\text { [13]. IVC may appear } \\
\text { expanded in the acute } \\
\text { phase or shrunken/fibrotic } \\
\text { in chronic phase [16]. }\end{array}$ & $\begin{array}{l}\text { Acute thrombus has } \\
\text { high T1WI and high } \\
\text { T2WI signal intensity. } \\
\text { Chronic thrombus has a } \\
\text { high T1WI and low } \\
\text { T2WI signal intensity. } \\
\text { Calcified thrombi will } \\
\text { demonstrate gradient } \\
\text { echo susceptibility } \\
\text { artifact. No DWI } \\
\text { restriction or contrast } \\
\text { enhancement [13]. IVC } \\
\text { may appear expanded } \\
\text { in the acute phase or } \\
\text { shrunken/fibrotic in } \\
\text { chronic phase [16]. }\end{array}$ & $\begin{array}{l}\text { Anechoic to hypo- } \\
\text { echoic focus within } \\
\text { the IVC lumen } \\
\text { which will becomes } \\
\text { more echogenic } \\
\text { with chronicity. } \\
\text { IVC will } \\
\text { demonstrate } \\
\text { incompressibility, } \\
\text { decreased blood } \\
\text { velocity and } \\
\text { monophasic } \\
\text { waveforms. } \\
\text { Posterior acoustic } \\
\text { shadowing present } \\
\text { if thrombus is } \\
\text { calcified [13]. IVC } \\
\text { may appear } \\
\text { expanded in the } \\
\text { acute phase or } \\
\text { shrunken/fibrotic in } \\
\text { chronic phase [16]. }\end{array}$ & $\begin{array}{l}\text { No associated } \\
\text { radiotracer } \\
\text { uptake. }\end{array}$ & $\begin{array}{l}\text { Acute to subacute } \\
\text { bland thrombus is } \\
\text { not seen on } \\
\text { conventional } \\
\text { radiography; } \\
\text { Chronic/calcified } \\
\text { thrombus may be } \\
\text { seen as a radiopaque } \\
\text { focus in the general } \\
\text { topography of the } \\
\text { IVC [13]. }\end{array}$ & $\begin{array}{l}\text { Intraluminal } \\
\text { filling defect } \\
\text { within an } \\
\text { opacified IVC } \\
\text { lumen [13]. }\end{array}$ \\
\hline $\begin{array}{l}\text { Tumor } \\
\text { Thrombus }\end{array}$ & $\begin{array}{l}\text { Enhancing soft tissue } \\
\text { mass in the IVC lumen }+/- \\
\text { expansion of the vessel; } \\
\text { tumor may arise directly } \\
\text { from the IVC in the case } \\
\text { of leiomyosarcoma or } \\
\text { spread contiguously into } \\
\text { the IVC through the } \\
\text { venous vasculature of a } \\
\text { malignant nearby organ } \\
\text { such as the kidney, liver, } \\
\text { or adrenal glands [16]. }\end{array}$ & $\begin{array}{l}\text { Enhancing soft tissue } \\
\text { mass in the IVC lumen } \\
\text { +/-expansion of the } \\
\text { vessel; tumor may arise } \\
\text { directly from the IVC } \\
\text { in the case of } \\
\text { leiomyosarcoma or } \\
\text { spread contiguously } \\
\text { into the IVC through } \\
\text { the venous vasculature } \\
\text { of a malignant nearby } \\
\text { organ such as the } \\
\text { kidney, liver or adrenal } \\
\text { glands [16]. Restricted } \\
\text { DWI is often present; } \\
\text { intrinsic T1WI/T2WI } \\
\text { signal characteristics } \\
\text { depend on tumor type } \\
\text { [16]. }\end{array}$ & $\begin{array}{l}\text { Echogenic soft } \\
\text { tissue mass in the } \\
\text { IVC lumen }+/- \\
\text { expansion of the } \\
\text { vessel; tumor } \\
\text { thrombus will } \\
\text { demonstrate color } \\
\text { Doppler flow } \\
\text { indicating } \\
\text { vascularity [16]. }\end{array}$ & $\begin{array}{l}\text { Radiotracer } \\
\text { uptake by } \\
\text { tumor/tumor } \\
\text { thrombus on } \\
{ }^{18} \text { F-FDG-PET } \\
{[16] .}\end{array}$ & $\begin{array}{l}\text { Not seen on } \\
\text { conventional } \\
\text { radiography. }\end{array}$ & $\begin{array}{l}\text { Intraluminal } \\
\text { filling defect } \\
\text { within an } \\
\text { opacified IVC } \\
\text { lumen [13]. }\end{array}$ \\
\hline Fat Embolism & $\begin{array}{l}\text { Portal venous phase } \\
\text { contrast enhanced CT } \\
\text { demonstrates a fat density } \\
\text { focus within an opacified } \\
\text { IVC lumen. Focus may be } \\
\text { isolated or rarely, extend } \\
\text { contiguously from an } \\
\text { adjacent renal } \\
\text { angiomyolipoma [19, 20, } \\
\text { 24]. }\end{array}$ & $\begin{array}{l}\text { T1WI/T2WI hyper- } \\
\text { intense focus within the } \\
\text { IVC lumen. Focus may } \\
\text { be isolated or rarely, } \\
\text { extend contiguously } \\
\text { from an adjacent renal } \\
\text { angiomyolipoma. No } \\
\text { contrast enhancement; } \\
\text { saturation on fat } \\
\text { saturation sequences } \\
{[19,20,24] \text {. }}\end{array}$ & $\begin{array}{l}\text { Hyper-echoic focus } \\
\text { in the IVC lumen. } \\
\text { Focus may be } \\
\text { isolated or rarely, } \\
\text { extend contiguously } \\
\text { from an adjacent } \\
\text { renal } \\
\text { angiomyolipoma } \\
{[19,20,24] \text {. }}\end{array}$ & $\begin{array}{l}\text { No associated } \\
\text { radiotracer } \\
\text { uptake. }\end{array}$ & $\begin{array}{l}\text { Not seen on } \\
\text { conventional } \\
\text { radiography. }\end{array}$ & $\begin{array}{l}\text { Intraluminal } \\
\text { filling defect } \\
\text { within an } \\
\text { opacified IVC } \\
\text { lumen [13]. }\end{array}$ \\
\hline
\end{tabular}

Table 2 (continued on next page): Differential diagnosis table for IVC Cement Thrombus. 


\begin{tabular}{|c|c|c|c|c|c|c|}
\hline & CT & MRI & US & PET & X-Ray & $\begin{array}{l}\text { Catheter } \\
\text { Venography }\end{array}$ \\
\hline $\begin{array}{l}\text { Calcification of } \\
\text { the IVC }\end{array}$ & $\begin{array}{l}\text { High density irregular } \\
\text { plaques along the wall of } \\
\text { the IVC }[17,21,23]\end{array}$ & $\begin{array}{l}\text { Irregular foci of } \\
\text { gradient echo } \\
\text { susceptibility artifact } \\
\text { along the wall of the } \\
\text { IVC }[17,21,23] .\end{array}$ & $\begin{array}{l}\text { Hyper-echogenicity } \\
\text { along the wall of the } \\
\text { IVC with posterior } \\
\text { acoustic shadowing } \\
{[17,21,23] .}\end{array}$ & $\begin{array}{l}\text { No associated } \\
\text { radiotracer } \\
\text { uptake. }\end{array}$ & $\begin{array}{l}\text { Radiopaque foci } \\
\text { along the } \\
\text { distribution of } \\
\text { the IVC [21]. }\end{array}$ & $\begin{array}{l}\text { Completely } \\
\text { opacified IVC } \\
\text { lumen without } \\
\text { filling defect [21]. }\end{array}$ \\
\hline $\begin{array}{l}\text { Artifactual filling } \\
\text { defect of the IVC }\end{array}$ & $\begin{array}{l}\text { Filling defect which } \\
\text { resolves with delayed or } \\
\text { reformatted imaging [17, } \\
22,23] \text {. }\end{array}$ & $\begin{array}{l}\text { Filling defect which } \\
\text { resolves with delayed } \\
\text { or reformatted imaging } \\
{[17,22,23] \text {. }}\end{array}$ & $\begin{array}{l}\text { Not seen on } \\
\text { sonography. }\end{array}$ & $\begin{array}{l}\text { Not seen on } \\
\text { nuclear } \\
\text { imaging. }\end{array}$ & $\begin{array}{l}\text { Not seen on } \\
\text { conventional } \\
\text { radiography. }\end{array}$ & $\begin{array}{l}\text { Ill-defined filling } \\
\text { defect at the level } \\
\text { of the renal veins } \\
{[22] .}\end{array}$ \\
\hline
\end{tabular}

Table 2 (continued): Differential diagnosis table for IVC Cement Thrombus.

\section{ABBREVIATIONS}

$\mathrm{CT}=$ Computed Tomography

DVT $=$ Deep Vein Thrombosis

DWI $=$ Diffusion Weighted Imaging

18F-FDG = Fluorine-18 Fluorodeoxyglucose

$\mathrm{GE}=$ General Electric

IVC $=$ Inferior Vena Cava

$\mathrm{kVp}=$ Peak Kilovoltage

$\mathrm{mA}=$ Milliampere

$\mathrm{mAs}=$ Milliampere-seconds

MRI = Magnetic Resonance Imaging

PET $=$ Positron Emission Tomography

PVP = Percutaneous Vertebroplasty

T1WI $=$ T1 Weighted Imaging

$\mathrm{T} 2 \mathrm{WI}=\mathrm{T} 2$ Weighted Imaging

US $=$ Ultrasound

\section{KEYWORDS}

IVC; Filter; Polymethyl Methacrylate; Intravasation; Bone; Cement; Vertebroplasty; Embolus; Embolism

\section{Online access}

This publication is online available at:

www.radiologycases.com/index.php/radiologycases/article/view/4139

\section{Peer discussion}

Discuss this manuscript in our protected discussion forum at: www.radiolopolis.com/forums/JRCR

\section{Interactivity}

This publication is available as an interactive article with scroll, window/level, magnify and more features. Available online at www.RadiologyCases.com

\section{Published by EduRad}

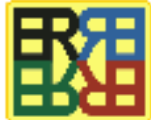

www.EduRad.org 